\title{
AJUSTES NUM BARÔMETRO POLÍTICO: SUGESTÕES PARA A MENSURAÇÃO DA PRESSÃO DE ENTIDADES SINDICAIS SOBRE DECISORES POR MEIO DA COMPARAÇÃO DAS AGENDAS LEGISLATIVAS DA CNI E DA CUT (2015-2017)
}

\author{
José Augusto Harmann ${ }^{1}$ \\ Igor Sulaiman Said Felicio Borck ${ }^{2}$ \\ Edilson Montrose de Aguiar Jr. ${ }^{3}$
}

\section{Resumo}

Visando contribuir ao desenvolvimento metodológico no que se refere à mensuração de interesses de grupos em relação ao Parlamento, propõe-se não apenas cotejar as posições manifestas de entidades sindicais em relação ao processo legislativo, mas comparar entidades sindicais de natureza diversa e, possivelmente, de interesses contraditórios. Deste modo, comparou-se os interesses manifestos nas Agendas Legislativas da CUT e da CNI entre os anos de 2015 e 2017, avaliando a correspondência (positiva ou negativa) entre os interesses de cada entidade em relação ao resultado do processo legislativo. Além de verificar as diferenças entre a correspondência de cada entidade, também sugeriu-se a hipótese de que ao adotar uma postura mais reativa em relação às proposituras em trâmite, isto é, preponderantemente divergente, a entidade tenderia a apresentar um resultado mais positivo, uma vez que as proposituras não culminam, em sua maioria, em novas normas jurídicas. Contudo, o resultado, ainda que aponte para uma ação mais reativa da CUT do que da CNI, apresenta uma correspondência similar nos dois casos. Assim, também não foi possível afirmar, nesta pesquisa, haver maior força ou real influência na produção legislativa de uma entidade em relação à outra, o que possivelmente é explicado pelo curto período de produção da Agenda da CUT (iniciada em 2015), num ambiente político conturbado e atípico (Impeachment da Presidente da República).

Palavras-chave: Índice de correspondência; Agenda Legislativa; CUT; CNI.

\section{Resumen}

Con el fin de contribuir al desarrollo metodológico en lo que se refiere a la medición de intereses de grupos en relación al Parlamento, se propone no sólo cotejar las posiciones manifiestas de entidades sindicales en relación al proceso legislativo, sino comparar entidades sindicales de naturaleza diversa y, posiblemente, con intereses contradictorios. De este modo, se compararon los intereses manifestados en las Agendas Legislativas de la CUT y de la CNI entre los años 2015 y 2017, evaluando la correspondencia (positiva o negativa) entre los intereses de cada entidad en relación al resultado del proceso legislativo. Además de verificar las diferencias entre la correspondencia de cada entidad, también se sugirió la hipótesis de que al adoptar una postura más reactiva en relación a las proposiciones en trámite, es decir, preponderantemente divergente, la entidad tendería a presentar un resultado más positivo, una ya que las proposiciones no culminan, en su mayoría, en nuevas normas jurídicas. Sin embargo, el resultado, aunque apunta a una acción más reactiva de la CUT que de la CNI, presenta una correspondencia similar en ambos casos. Así, no fue posible afirmar, en esta investigación, que hay mayor fuerza o real influencia en la producción legislativa de una entidad en

\footnotetext{
${ }^{1}$ Mestre e doutorando em Ciência Política; Universidade Federal do Paraná; jose.hartmann@ escola.pr.gov.br.

${ }^{2}$ Mestrando em Ciência Política; Universidade Federal do Paraná; iborcki@ hotmail.com.

${ }^{3}$ Mestre e doutorando em Ciência Política; Universidade Federal do Paraná; eciensoc@gmail.com.
} 
relación a la otra, lo que posiblemente se explica por el corto período de producción de la Agenda de la CUT (iniciada en 2015), en un ambiente político turbulento (el Ipeachment de la presidenta Dilma Rousseff).

Palabras clave: Índice de correspondencia; Agenda Legislativa; CUT; CNI.

\begin{abstract}
In the objective of contribute to the methodological development regarding the measurement of group interests vis-à-vis Parliament, it is proposed not only to compare the manifested positions of trade union entities in relation to the legislative process, but to compare trade union entities of different natures and, possibly, with conflicts of interests. In this way, the interests expressed in the Legislative Agendas of the CUT and the CNI between the years 2015 and 2017 were compared, evaluating the correspondence (positive or negative) between the interests of each entity in relation to the outcome of the legislative process. In addition to verifying the differences between the correspondence of each entity, the hypothesis was also suggested that when adopting a more reactive posture in relation to the proposals in process, that is to say, preponderantly divergent, the entity would tend to present a more positive result, a proposals do not culminate, for the most part, in new legal norms. However, the result, although it points to a more reactive action of the CUT than of the CNI, presents a similar correspondence in both cases. Thus, it was not possible to state in this research that there is a greater force or real influence on the legislative production of one entity over the other, possibly explained by the short production period of the CUT Agenda (begun in 2015), in a political environment troubled and atypical (Impeachment of the President of the Republic).
\end{abstract}

Keywords: Correspondence index; Legislative Agenda; CUT; CNI.

\title{
1. INTRODUÇÃO
}

A literatura acerca da ação política de grupos de interesse ligados a temas econômicos, como empresários, aponta, nos últimos anos, para a robustez dessa ação e para o "sucesso" nos seus resultados. Contudo, uma vez que há risco de se sobrevalorizar um "sucesso", dada a posição tomada pela entidade, propõe-se não somente cotejar as posições manifestas de entidades sindicais em relação ao processo legislativo, mas a comparação entre entidades sindicais diversas - de interesses, possivelmente, contraditórios.

Os trabalhos basilares desse campo, de Wagner Mancuso, propuseram o exame das posições manifestas do empresariado em relação ao resultado do processo decisório (MANCUSO, 2007). Entretanto, verifica-se que as proposituras tramitadas no legislativo não culminam em novas normas jurídicas (leis, decretos, emendas, etc.), o que tende a sobrevalorizar as posições convergentes (em relação à essas proposituras) dos grupos de interesses como "sucessos". Decorre disso, a necessidade de se pensar arranjos visando maior rigor metodológico sobre a mensuração dos resultados da pressão exercida por grupos em relação aos decisores.

É sabido que entidades sindicais, como a CNI, algumas Federações Estaduais da Indústria ou a Confederação Nacional das Instituições Financeiras (CNF), acompanham as proposituras em 
trâmite nos Legislativos nacional ou locais. Além disso, algumas dessas entidades divulgam uma Agenda Legislativa, manifestando interesses em relação à essas proposituras. No trabalho já citado sobre o acompanhamento da relação entre esse posicionamento de interesses de uma entidade sindical (a CNI) e o resultado do processo legislativo, Pralon cotejou os interesses manifestos na Agenda Legislativa da Indústria ao resultado legislativo do Congresso Nacional, verificando um "sucesso" da CNI de mais de 60\% (MANCUSO, 2007).

\section{METODOLOGIA}

Observamos, então, as Agendas Legislativas (AL) da CNI (Confederação Nacional da Indústria) e da CUT (Central Única dos Trabalhadores), para os anos de 2015 e 2017, em relação ao Congresso Nacional. A hipótese apresentada sugere que uma posição reativa $a^{4}$ tende a representar uma maior correspondência. Os resultados, entretanto, ainda que apontem para uma ação mais reativa da CUT do que da CNI, apresentam uma correspondência similar (em grande medida, correspondente nos dois casos, CNI e CUT). Assim, não foi possível afirmar, nesta pesquisa, haver maior força ou real influência na produção legislativa de uma entidade em relação à outra.

Contudo, propomos, para além do cotejamento que a pesquisa quantitativa permite, avançar numa análise qualitativa. Nesse caso, avaliamos o teor (tema) das proposituras acompanhadas pelas entidades sindicais em questão, o que indicou o avanço de uma agenda legislativa negativa aos interesses manifestos da CUT, assim como um resultado negativo.

Também não se pode sustentar a hipótese de que uma posição mais reativa incida em maior ganho, o que é possivelmente explicado pelo curto período de produção da Agenda da CUT (iniciada em 2015), num ambiente político conturbado e atípico (Impeachment da Presidente da República) - carecendo-se de uma análise futura, quando houver uma produção mais numerosa da Central Única dos Trabalhadores (se isso vier a se concretizar).

Define-se, portanto, que a correspondência entre as entidades e o processo legislativo possa ser considerada um importante item para a mensuração da pressão política exercida pelos grupos de interesse. Como categoria de análise, trabalhamos com essa ideia, que se baseia no cruzamento dos dados das posições da CUT e da CNI, expressas em suas Agendas Legislativas, com o resultado

\footnotetext{
${ }^{4}$ Por posição reativa, entende-se a posição manifesta dos interesses da entidade sindical em relação à alguma propositura, na Agenda Legislativa, de maneira "divergente". Nas Agendas Legislativas, entidades como a CNI e a CUT se posicionam de modo "convergente" ou "divergente" (com ou sem ressalvas) em relação à proposituras diversas. Quando o resultado do processo legislativo acompanha o posicionamento manifesto da entidade, afirmamos haver uma correspondência (entre os interesses manifestos e o resultado).
} 
legislativo no período estudado. Nesse sentido, quando a decisão legislativa está de acordo com as expectativas das entidades, categorizamos como correspondência. O desenvolvimento dessa categoria de correspondência se dá a partir da exposição de Paulo Roberto N. Costa e Igor Sulaiman S. F. Borck, na ANPOCS de 2017 (COSTA; BORCK, 2017).

A ideia de correspondência proposta neste trabalho, pode ser dividida em duas partes, a primeira delas é a correspondência positiva, que ocorre quando verificamos que a posição da entidade estudada é convergente a um projeto de lei qualquer, e esse projeto se torna nova norma jurídica, e chamamos de correspondência negativa, quando a posição da entidade observada é divergente a um projeto de lei qualquer, e este é arquivado, retirado pelo autor ou rejeitado.

A correspondência positiva é aquela que traz ganhos reais para as demandas pautadas pelas entidades, enquanto a correspondência negativa, em tese, demanda esforços das entidades para barrar algum projeto divergente a seus interesses, ou seja, um gasto político. Novamente em Mancuso, retiramos essa orientação, como se pode ver no quadro abaixo:

\begin{tabular}{|l|l|l|}
\hline \multirow{2}{*}{ Impacto sobre o status quo } & Resultado da decisão \\
\cline { 2 - 3 } & Sucesso & Insucesso \\
\hline Status quo muda & Ganho & Perda \\
\hline Status quo mantém-se & Alívio & Frustração \\
\hline
\end{tabular}

Fonte: MANCUSO, 2007.

Entretanto, a categoria analítica chamada de correspondência não pretende - conforme enunciamos nos objetivos desse trabalho - aferir um grau específico de sucesso ou insucesso da ação política de grupos organizados, mas tem como objetivo, elucidar os dados sobre a correspondência das demandas das AL e decisão legislativa produzida pelo Congresso Nacional. Afirma-se a temeridade na afirmação de "sucesso" a partir desse cotejamento, dada a possibilidade de viés derivado da posição inicial, manifesta, da entidade.

Considera-se que a correspondência entre as posições manifestas das entidades sindicais empresariais cotejadas com o resultado do processo legislativo não indica necessariamente em sucesso ou insucesso da Indústria.

Trata-se, portanto, de uma pesquisa que busca agregar elementos quantitativos com qualitativos (quali-quanti). Deste modo, inicialmente, propomos cotejar as posições manifestas das entidades representativas de setores diversos (para não se dizer antagônicos), a CNI, representante dos interesses patronais da Indústria, e a CUT, representante de trabalhadores associados a alguns 
sindicatos de trabalhadores, com o resultado do processo legislativo no Congresso Nacional, entre 2015 e 2017. Em seguida, propôs-se desenvolver um passo que permitisse ganhos analíticos. Nessa segunda parte, de natureza descritiva, foram consideradas as proposituras por tema, objetivando a realização de inferências ao se relacionar tema, correspondência e legislatura.

\section{REVISÃO DE LITERATURA}

Os trabalhos acerca da atuação do empresariado em relação à política no Brasil indicam para além da desconfiança de um encerramento projetado pelo modelo corporativista (MARTINS, 1985; SCHMITTER, 1971) ou de uma fragmentação debilitadora da representação de interesses (DOCTOR, 2002) - uma maior capacidade organizativa e maior atuação em relação ao processo decisório, culminando na constatação de que, com a democratização, o Parlamento passou a ser alvo de suas preocupações e pressão (BOSCHI; DINIZ, 2000; MANCUSO, 2007). Desse novo ambiente identificado, afluíram estudos acerca do lobby no Brasil, uma vez que se identificava um modelo híbrido pluralista-corporativista (BOSCHI; DINIZ, 2000; DINIZ, 1997; MANCUSO, 2007). Mancuso avaliou a manifestação de interesses acerca das propostas em trâmite no Congresso Nacional acompanhadas pela CNI e as comparou com o resultado final do processo legislativo, obtendo, assim, um índice de sucesso da Indústria (MANCUSO, 2007). Entretanto, rigorosamente, cabe aquelas considerações lançadas inicialmente.

Se, em relação ao empresariado, os estudos em relação a lobby parlamentar são em bom número, por sua vez, aqueles que se referem a trabalhadores, são em quantidade mais modesta. Entre os poucos, temos as investigações de Costa (2016) e também Guilmo e Del Passo (2017). O primeiro analisou a atuação do DIAP (Departamento Intersindical de Assessoria Parlamentar) durante o transcorrer da Assembleia Nacional Constituinte. Para Costa (op.cit.), o DIAP conseguiu, em parte, fazer valer suas opiniões no texto constitucional, tanto assim, que este se caracteriza pelo detalhamento das normas que regulam o trabalho. Segundo o autor, esse resultado positivo foi fruto das seguintes capacidades demonstradas pelo órgão: eficácia em forjar consensos entre as centrais sindicais, conseguir convencer constituintes através de qualificação técnica das propostas legislativas apresentadas, pressão sobre os constituintes via atribuição de notas a cada um deles e publicização das atividades do órgão via boletins e jornal próprio. Já a pesquisa de Guilmo e Del Passo (op.cit.), tem a mesma preocupação que o nosso estuda ao comparar a atuação de CNI e CUT durante o segundo governo Lula (2007-2010), e conclui que a referida entidade patronal não logrou êxito no período, enquanto que a central sindical de trabalhadores teria obtido conquistas via 
movimentações grevistas. Veremos adiante que isso contrasta com a nossa pesquisa, a qual, no período do segundo governo Dilma, o resultado é o inverso. Os autores ainda diferenciam lobby, que teria sido a tática mais comumente utilizada pela central empresarial, de "mobilização popular" via greve, expediente preferido pela central trabalhista. Também destacam que ambas estariam unidas na campanha eleitoral de 2006, outorgando apoio à candidatura Lula. Ainda sobre o movimento sindical, se destacam os trabalhos de Tatagiba e Galvão (2019) e Boito Jr. e Marcelino (2010) sobre ativismo sindical. Ambas as pesquisas se basearam em dados do DIEESE (Departamento Intersindical de Estatística e Estudos Socioeconômicos) para afirmar que, de 2008 a 2013, houve um aumento contínuo de greves no Brasil, seguido por dois anos de retração (2014 e 2015), para depois retomar com força em 2016. Ainda está por se investigar se o aumento do ativismo grevista está correlacionado, negativamente ou positivamente, com a atividade de lobby por parte do sindicalismo de trabalhadores, junto ao Legislativo. De todo modo, é no ano de 2015 que a CUT lança sua primeira edição de agenda legislativa, voltando a repetir em 2017.

O estudo de Santos et.al. (2017) sobre o lobby é de grande valia por conta do ineditismo dos achados. Via survey, os autores conseguiram mapear as estratégias utilizadas pelos grupos de pressão. Os autores basearam seu universo nas 179 entidades de classe de nível superior (de empresários, trabalhadores, setor público, ONGs) a operarem na casa legislativa durante o biênio 2011-2012. O survey aplicado obteve uma taxa de resposta de 36,3\%, o que, segundo os autores (SANTOS et.al., p.18), é considerado satisfatório em comparação a pesquisas semelhantes. As conclusões gerais apuraram que, de acordo com as entidades, há uma percepção de que é crescente a profissionalização da atividade lobista, materializando isto nos seguintes indicadores: setor dedicado exclusivamente a esta atividade e com orçamento próprio; profissionais com experiência de alguns anos na atividade. Entre as arenas de atuação, constam o Legislativo, Executivo, Judiciário e Agências Reguladoras (nesta última atuam em especial os grupos de interesses ligados ao empresariado). Entre as estratégias, elencam-se: corpo a corpo junto a parlamentares, acompanhamento das comissões permanentes das casas legislativas, participação em audiências públicas, contato com consultorias legislativas, coalizões com outros grupos de pressão, redação e apresentação de trabalhos técnicos. Algumas táticas, como a de mobilização de sua base de representados e envio de e-mails, são próprias de serem empreendidas por organizações de trabalhadores. Por fim, quanto a eficácia da atividade lobista, as entidades disseram que ela vale a pena, contudo, para se lograr êxito, variados fatores contam além do lobby em si.

A análise de Zampieri (2013) identificou que há congruência entre três modelos teóricos (distributivista, informacional, partidário) mobilizados para se explicar o funcionamento do 
Legislativo com os três momentos de decisão para a produção de leis (indicação da relatoria, formulação de parecer do relator, apreciação pela comissão). O modelo distributivista afirma que, por conta da conexão eleitoral geográfica, os representantes tendem a perseguir políticas benéficas ao seu eleitorado. E seria essa premissa que os parlamentares levariam em conta numa espécie de ganhos de troca com os demais parlamentares no primeiro momento de decisão, no caso, aquele em que o Presidente da Comissão indicaria um parlamentar para ser relator de um projeto de lei. De acordo com Zampieri, nesse primeiro momento, a possibilidade de êxito do lobby empreendido por grupos de pressão é baixa, tendo em conta que os interesses individuais dos parlamentares tendem a se sobrepor. Já num segundo momento, o da formulação do parecer do relator sobre determinado projeto de lei, melhor explicado pelo modelo informacional, a possibilidade de êxito lobista é mais provável. E assim o seria, pelo fato de que com o intuito de se reduzir as incertezas fruto da carência de informações sobre alguns temas, o relator pode estar disponível a ouvir as opiniões dos grupos de pressão afetados pelo projeto de lei. Já o terceiro momento, o de apreciação do projeto por parte da Comissão, é adequadamente explanado pelo modelo partidário, pois as legendas podem determinar o posicionamento de seus parlamentares. Nesse último momento, a probabilidade de êxito do lobby é menor do que o anterior e caberiam aos representantes dos grupos de pressão o convencimento dos demais membros da comissão. Zampieri (2013) conclui que o momento de formulação de parecer por parte do relator de um projeto é o mais propício a que a atividade lobista logre êxito.

Para a análise do lobby, a Agenda Legislativa da Indústria (AL) mostrou-se um importante instrumento a ser investigado. A Agenda pode ser considerada não apenas como um anuário da manifestação de interesses da CNI, mas também um instrumento de pressão sobre os decisores, uma vez que se trata de uma publicização com interesses embasados. Ainda assim, considerar o acompanhamento do processo decisório e a produção da AL enquanto lobby, tomando a comparação do posicionamento em relação às propostas tramitadas no Congresso com os interesses manifestos na Agenda como sucessos ou insucessos, requer, antes, algumas ponderações, sobretudo ao tratar o lobby como sinônimo de pressão, o que indica a existência de uma atividade contínua de pressão.

Além disso, ao se considerar como um sucesso uma correlação positiva entre uma posição manifesta e o resultado do processo legislativo, pressupõe-se que tal resultado procede da ação do grupo de interesse. Ademais, ainda que haja tal pressão, uma proposição pode ser aprovada (ou não) por inúmeros motivos e não é automática a correlação da sua aprovação com a pressão de determinado grupo. 
Deve-se considerar que a posição inicial tomada por uma entidade pode determinar o índice (Cf. FACCI, 2017; HARTMANN, 2015), o que se deve ao fato de que o processo legislativo comumente não culmina na formulação de novas leis. Assim, no caso de uma posição preponderantemente reativa da entidade sindical, tende-se a um maior "sucesso", inflado pela inclinação de arquivamento das propostas - o que é apresentado como hipótese neste trabalho.

Contudo, não se trata de abandonar a proposta de medir influência, mas, sim, a de contribuir na construção de mecanismos de avaliação da influência e ação política, tendo-se como base a confrontação dos interesses manifestos na AL da CNI em relação ao processo legislativo na Câmara dos Deputados. Porém, propõe-se que a averiguação da correspondência entre as posições manifestas e do resultado do processo legislativo seja comparado, visto que ainda se identifica uma lacuna na literatura em apresentar um índice seguro de aferição dos resultados da pressão de empresários sobre o parlamento. Para isso, neste trabalho foi proposto o acompanhamento da Agenda Legislativa para as Relações de Trabalho (ALCUT), da Central Única dos Trabalhadores (CUT) para comparação com a Agenda Legislativa da CNI.

\section{RESULTADOS:}

\subsection{AS AGENDAS LEGISLATIVAS DA CENTRAL ÚNICA DOS TRABALHADORES}

$\mathrm{Na}$ ALCUT, ainda que a entidade acompanhe um considerável número de projetos (194 em 2015, 203 em 2016 e 258 em 2017), não há manifestação de posição em todas as proposituras acompanhadas. Ao menos, a divulgação de posição ocorre somente em 6 proposituras para 2015, 23 em 2016 e 2 em 2017. A opção de divulgação de posição deu-se somente para os projetos da pauta prioritária da entidade. Em 2015, das 6 propostas avaliadas, 5 foram consideradas convergentes e uma convergente com ressalvas (2015) - serão agregadas como convergentes.

A partir do ano de 2016, de modo inverso, a central sindical adota uma postura reativa. Todas as 23 propostas acompanhadas são negativas aos seus interesses (divergentes), o que indica uma distribuição concentrada em divergências (ALCUT, 2016). Abaixo, apresenta-se a tabela, agregando os posicionamentos "com ressalvas" ao valor simples ("convergente ou divergente").

Posição da entidade - CUT

\begin{tabular}{llll}
\hline & & Frequência & Percentual \\
\hline Posição & Convergente & 6 & 19,4 \\
& Divergente & 25 & 80,6 \\
\hline
\end{tabular}


Fonte: os Autores (2018)

Pode-se considerar que o ano de 2016 apresentou uma mudança política importante no país, em que a Presidente da República, do Partido dos Trabalhadores (PT), foi impedida no cargo. A reboque, mas já em 2017, a "Reforma Trabalhista" foi celeremente aprovada no Congresso e, novamente de modo veloz, sancionada pelo novo ocupante da função. Ainda assim, o teor dos projetos acompanhados em 2016 concentra-se na pauta contrária a mudanças nas regras trabalhistas (postas em discussão anteriormente a 2016). Para 2016, a CUT apontou como prioritários 23 proposições, e para 2017 a prioridade foi dada somente ao PLC no 38/2017 "Reforma Trabalhista" (com tramitação encerrada) e à PEC 287/2016 - "Reforma da Previdência" (em trâmite).

As demais proposituras com posicionamento podem explicar a mudança radical de posição de 2015 (totalmente não-reativa) para 2016 e 17 (totalmente reativa). O ano de 2015 marcou o início da nova legislatura, assim como o segundo mandato da presidente Dilma Rousseff. Entretanto, nesse, o Congresso se apresentava mais hostil à mandatária. O Departamento Intersindical de Assessoria Parlamentar, em sua Radiografia do Novo Congresso, de 2014, apontava para uma legislatura de relacionamento conturbado com a presidente, e com as seguintes características:

O Congresso eleito em 2014, renovado em 46,59\% na Câmara e em 81,48\% em relação às vagas em disputa no Senado, é pulverizado partidariamente, liberal economicamente, conservador socialmente, atrasado do ponto de vista dos direitos humanos e temerário em questões ambientais (DIAP, 2014, p.13).

Economicamente, o tema do "custo-Brasil", tão caro nos anos de 1990 e à ação e organização da CNI, conforme apresentou Mancuso (2007), foi novamente levantado com força. A legislatura 2015-2018 defenderá uma pauta mais liberalizante, propondo a diminuição de custos - o que implicava novas regras trabalhistas mais generosas aos interesses patronais. O DIAP expôs do seguinte modo a nova composição quanto às questões econômicas (centrais nas ALCUT):

Do ponto de vista econômico, o novo Congresso é mais liberal que o atual. Houve uma transferência da ordem de 60 parlamentares dos partidos de es-querda, centro-esquerda e centro, que reconheciam e defendiam um papel proativo do Estado na economia, para partidos de perfil mais liberal, além da eleição de liberais em substituição a parlamentares progressistas em partidos de centro. Perderam os que defendiam a presença do Estado na economia, inclusive como forma de evitar especulação ou abusos de preços, via concorrência, como é o caso dos bancos públi-cos, e ganharam os que entendem que o mercado é perfeito e que o Estado não deve atuar na atividade econômica, nem como regulador nem como produtor e fornecedor de bens ou serviços (DIAP, 2014, p. 14-15). 
Deste modo, se até 2014, quando elaborada a ALCUT de 2015, havia uma perspectiva mais "progressista" do ponto de vista da Central Sindical, com proposituras como a diminuição da carga horária sem diminuição de salários, a partir de 2015, o cenário se tornou mais hostil. Diante de um Congresso mais "conservador nos costumes" e "liberal na economia", ou então, menos adepto à propostas que beneficiassem os trabalhadores do ponto de vista da remuneração ou da quantidade de trabalho, a CUT adotará uma postura reativa.

Deste modo, conforme pode-se ver na tabela abaixo, as proposituras acompanhadas pela CUT a partir de 2016 focam em alterações de flexibilização do regime de trabalho, como a jornada intermitente, terceirização para atividade fim, de alterações nos regimes de trabalho no Serviço Público, mudanças nas regras previdenciárias e regulação mais rígida ao direito de greve e de negociação coletiva. Em 2017, o foco passa a ser duas únicas proposituras que estão nessa pauta mínima (trabalhista e previdenciária).

Em seguida, o quadro com as temáticas acompanhadas pelas ALCUT analisadas.

\begin{tabular}{|c|c|c|c|}
\hline 2017 & $\begin{array}{l}\text { Tipo das normas } \\
\text { jurídicas }\end{array}$ & Tema & Origem do PL \\
\hline & PLC n n $^{\circ} 38 / 2017$ & Reforma Trabalhista & Poder Executivo \\
\hline & PEC n ${ }^{\circ} 287 / 2016$ & Reforma da Previdência Social & Poder Executivo \\
\hline 2016 & $\begin{array}{l}\text { Tipo das normas } \\
\text { jurídicas }\end{array}$ & Tema & Origem do PL \\
\hline & PLC n n $^{\circ} 0 / 2015$ & Terceirização & PMDB \\
\hline & PLP no 257/2016: & $\begin{array}{l}\text { Setor Público (regras recuperação nos } \\
\text { estados) }\end{array}$ & Poder Executivo \\
\hline & PLP $1 / 2007$ & $\begin{array}{l}\text { Setor Público (limitação de gastos com } \\
\text { servidores) }\end{array}$ & Poder Executivo \\
\hline & PEC 241/2016 & Setor Público (novo regime fiscal) & Poder Executivo \\
\hline & PLP 92/2007 & Setor Público (limita fundações públicas) & Poder Executivo \\
\hline
\end{tabular}




\begin{tabular}{|c|c|c|}
\hline PLS n ${ }^{\circ} 327 / 2014$ & Setor Público (limita greves) & $\begin{array}{l}\text { Comissão Mista de } \\
\text { Consolidação da } \\
\text { Legislação Federal }\end{array}$ \\
\hline PEC n ${ }^{\circ} 18 / 2011$ & $\begin{array}{l}\text { Relações de Trabalho (trabalho a partir dos } 14 \\
\text { anos) }\end{array}$ & $\mathrm{PP}$ \\
\hline $\mathrm{PL} \mathrm{n}^{\circ} 450 / 2015$ & $\begin{array}{l}\text { Relações de Trabalho (regime "flexível" de } \\
\text { trabalho) }\end{array}$ & PSB \\
\hline $\mathrm{PL} \mathrm{n}^{\circ} 3.342 / 2015$ & $\begin{array}{l}\text { Relações de Trabalho (regime "flexível" de } \\
\text { trabalho) }\end{array}$ & SD \\
\hline PLS n ${ }^{\circ} 218 / 2016$ & $\begin{array}{l}\text { Relações de Trabalho (regime "flexível" de } \\
\text { trabalho) }\end{array}$ & PSDB \\
\hline $\mathrm{PL} \mathrm{n}^{\circ} 3.785 / 2012$ & $\begin{array}{l}\text { Relações de Trabalho (regime "flexível" de } \\
\text { trabalho) }\end{array}$ & PR \\
\hline $\mathrm{PL} \mathrm{n}^{\circ} 4.665 / 2016$ & $\begin{array}{l}\text { Relações de Trabalho (regime "flexível" de } \\
\text { trabalho) }\end{array}$ & PSD \\
\hline PL n ${ }^{\circ} 1.463 / 2011$ & $\begin{array}{l}\text { Relações de Trabalho (regime "flexível" de } \\
\text { trabalho) }\end{array}$ & PTB \\
\hline $\mathrm{PL} \mathrm{n}^{\circ} 8.294 / 2014$ & $\begin{array}{l}\text { Relações de Trabalho (regime "flexível" de } \\
\text { trabalho) }\end{array}$ & PV \\
\hline $\mathrm{PL} \mathrm{n}^{\circ} 726 / 2015$ & $\begin{array}{l}\text { Relações de Trabalho (regime "flexível" de } \\
\text { trabalho) }\end{array}$ & PCdoB \\
\hline $\mathrm{PL} \mathrm{n}^{\circ} 2.820 / 2015$ & $\begin{array}{l}\text { Relações de Trabalho (regime "flexível" de } \\
\text { trabalho) }\end{array}$ & PSD \\
\hline $\mathrm{PL} \mathrm{n}^{\circ} 6.906 / 2013$ & $\begin{array}{l}\text { Relações de Trabalho (regime "flexível" de } \\
\text { trabalho) }\end{array}$ & PSB \\
\hline $\mathrm{PL} \mathrm{n}^{\circ} 6.698 / 2013$ & $\begin{array}{l}\text { Relações de Trabalho (regime "flexível" de } \\
\text { trabalho) }\end{array}$ & PSDB \\
\hline $\mathrm{PL} \mathrm{n}^{\circ} 7.341 / 2014$ & Negociação Coletiva & PSD \\
\hline $\mathrm{PL} \mathrm{n}^{\circ} 4.193 / 2012$ & Negociação Coletiva & PSD \\
\hline PL n ${ }^{\circ} 6.411 / 2013$ & Negociação Coletiva & PMDB \\
\hline $\mathrm{PL} \mathrm{n}^{\circ} 4.977 / 2016$ & Negociação Coletiva & DEM \\
\hline
\end{tabular}




\begin{tabular}{|c|c|c|c|}
\hline & PLS n ${ }^{\circ} 211 / 2016$ & Negociação Coletiva & PSDB \\
\hline 2015 & $\begin{array}{l}\text { Tipo das normas } \\
\text { jurídicas }\end{array}$ & Tema & Origem do PL \\
\hline & MSC n ${ }^{\circ} 59 / 2008$ & Combate a rotatividade & Poder Executivo \\
\hline & PLS n ${ }^{\circ} 173 / 2015$ & Combate a rotatividade & PCdoB \\
\hline & MPV n ${ }^{\circ} 672 / 2015$ & Política de Valorização do Salário Mínimo & Poder Executivo \\
\hline & PEC n ${ }^{\circ} 231 / 1995$ & $\begin{array}{l}\text { Redução da Jornada de } \text { Trabalho sem } \\
\text { Redução de Salário }\end{array}$ & PCdoB \\
\hline & PL no $4.532 / 2012$ & Democratização nas relações de trabalho & PT \\
\hline & MPV n ${ }^{\circ} 676 / 2015$ & Fator Previdenciário & Poder Executivo \\
\hline
\end{tabular}

Fonte: os Autores (2018)

Os resultados obtidos pela Central apresentaram um índice satisfatório de correspondência aos seus interesses, porém, o $\mathrm{N}$ não é considerado seguro para inferências mais ousadas. Em relação à CNI, a CUT focou em número menor de propostas que a central patronal, adotando uma estratégia mais focada. Inicialmente, se esperava que a postura reativa implicasse numa maior correspondência, contudo, verifica-se que isso acaba por ser determinado pela composição do Congresso e dos temas tratados. Muito da correspondência da CUT é resultado das proposituras em tramitação, uma vez que a agenda de flexibilização do trabalho que estava em processo em 2016 ficou obsoleta diante da "Reforma Trabalhista" de 2017. Portanto, quanto ao teor das proposituras, a partir de 2015, a pauta da CUT é largamente derrotada, e sua posição reativa não foi capaz de garantir a reversão do quadro diante de um Congresso sabidamente pré-reformas liberalizantes no campo do trabalho e da previdência.

Em seguida, a tabela apresenta os resultados do cotejamento das posições manifestas da CUT em relação ao resultado do processo legislativo:

\begin{tabular}{llll}
\multicolumn{4}{c}{ Resultado CUT } \\
\hline Resultado & Fusentes & Frequência & Percentual \\
& Correspondentes & 24 & 77,4 \\
& Não correspondentes & 4 & 12,9 \\
& 3 & 9,7 \\
\hline
\end{tabular}


Tota

Note-se que grande parte das proposituras ainda estavam em tramitação, o que pode ser compreendido uma vez que o acompanhamento é recente (a partir de 2015), entre as correspondentes (4 no total) a distribuição é igual (2 dessas são convergentes, isto é, Correspondência Positiva, e 2 são divergentes, remetendo a uma Correspondência Negativa). Entre as não-correspondentes, todas as 3 são divergentes.

Entre essas 24 proposituras consideradas ausentes, 13 eram anteriores a 2015, isto é, anteriores à legislatura do acompanhamento dessas Agendas Legislativas (2015-2018), mas que foram reabertos pela legislatura atual - mas ainda continuavam em trâmite. $\mathrm{O}$ total de 11 dessas 24 proposituras foram protocoladas após o início de 2015.

Quando a posição foi divergente, portanto reativa, o índice foi de 50\% para correspondentes. Essa posição, contudo, representou 100\% dos casos de não-correspondência (as três proposituras nãocorrespondentes). Os valores, assim, não estão de acordo com a hipótese de que uma posição reativa por parte da entidade tende a ter maior correspondência, ainda que seja temerário afirmar que esse caso confirme a hipótese.

O mesmo pode-se verificar quanto ao posicionamento convergente - que resulta em menor correspondência. Foram 50\% quando consideradas convergentes, mas todas as não correspondentes (3) estão entre as divergentes. Portanto, ainda que o $\mathrm{N}$ seja baixo, o que dificulta uma conclusão segura, não se pode sustentar a hipótese.

Numa tabela cruzada, os dados se apresentam do seguinte modo:

\begin{tabular}{|c|c|c|c|c|c|}
\hline & & \multicolumn{3}{|l|}{ Resultado } & \multirow[b]{2}{*}{ Total } \\
\hline & & Não categorizado & Correspondente & $\begin{array}{l}\text { Não } \\
\text { correspondente }\end{array}$ & \\
\hline \multirow[t]{3}{*}{ Posição } & Convergente & 4 & 1 & 0 & 5 \\
\hline & Convergente com ressalvas & & 1 & 0 & 1 \\
\hline & Divergente & 21 & 2 & 2 & 25 \\
\hline Total & & 25 & 4 & 2 & 31 \\
\hline
\end{tabular}

Fonte: Os Autores (2018)

Nesse caso, são categorizadas apenas 6 proposituras. A tabela, contudo, ilustra melhor a distribuição equitativa quando o resultado é correspondente e a concentração da posição divergente 
quando o resultado não é correspondente (o que também acreditamos não serem dados fortemente confiáveis dado o baixo $\mathrm{N}$ ).

\subsection{AS AGENDAS LEGISLATIVAS DA CONFEDERAÇÃO NACIONAL DA INDÚSTRIA}

As Agendas da CNI apresentaram um total de 249 proposituras acompanhadas. Desse total, 59 foram classificadas como convergentes aos interesses da entidade. 19 convergentes com ressalvas. Juntas essas duas categorias corresponderam a $31,25 \%$ do total. Divergentes foram 47 e divergentes com ressalvas 3 (total de 20,08\%). 121 proposituras não tiveram posição da CNI em 2017, sendo descartadas dos testes. Ao aglutinar os itens com ressalvas às categorias convergente e divergente, sem considerar esses 121 projetos sem posição, verifica-se uma concentração em posições convergentes da entidade, em detrimento de posições divergentes. Portanto, verifica-se que a CNI optou por uma postura nãoreativa, de modo contrário ao da CUT. Dentre as 128 propostas válidas, Novas Normas Jurídicas representaram 22 (8,8\%). Arquivadas, com Perda de Eficácia, apensadas ou retiradas pelo Autor (Arquivadas) somaram 35. Outras 185 estavam em trâmite, sendo que dessas, 28 eram anteriores a 2015. A pesquisa desconsiderou, em partes, proposituras apensadas.

Considerando a correspondência/não-correspondência entre as posições manifestas da CNI, e desconsiderando-se a categoria testada anteriormente, de engavetados, portanto, comparando somente a posição da entidade com novas normas jurídicas, arquivadas, retiradas ou rejeitadas, obteve-se um total de 31 propostas.

\section{Posição CNI * Resultado (Tabela Cruzada)}

\begin{tabular}{l|l|l|l}
\hline Autor & N projetos & Correspondência & Não Correspondência \\
\hline Câmara dos Deputados & 7 & 5 & 2 \\
Senado da República & 11 & 9 & 2 \\
Poder Executivo & 13 & 8 & 5 \\
Total & $\mathbf{3 1}$ & $\mathbf{2 2}$ & $\mathbf{9}$ \\
\hline
\end{tabular}

Fonte: os Autores (2018)

Dessas, 22 tiveram resultado correspondente entre posição da entidade e processo legislativo, enquanto 9 foram classificadas como não-correspondentes. Considerando a Correspondência Positiva e a Correspondência Negativa, foram 18 proposituras com CP e 4 com CN, o que aponta para um resultado relativamente expressivo para as posições correspondentes da CNI e para ganhos efetivos. 
Tais resultados, indicam tanto que a CNI obteve uma correspondência razoável - 58,06\% na avaliação de CP, quanto para a estratégia daqueles envolvidos na produção, acompanhamento e decisão da ALI. Quando se observa a Correspondência Negativa, que indica uma posição reativa da entidade, o índice cai para 12,90\%. Quando se considera o trabalho de Mancuso, verifica-se que a CNI adotava no período (1996-2003) uma postura mais reativa. Mancuso concluiu que a CNI obteve um indice de sucesso na casa de 66,7\% (144 propostas). Dessas, contudo, 90 foram arquivadas, retiradas ou rejeitadas, o que corresponde a 62,5\% (MANCUSO, 2007, p. 153) o que aponta para o efeito da posição adotada (majoritariamente divergente) pela entidade no resultado da correspondência, ou, conforme Mancuso, sucesso.

Abaixo, seguem as temáticas das proposituras acompanhadas pela CNI nas Agendas Legislativas avaliadas, iniciando pelo quadro geral.

Quadro 1 - Temática das proposituras da agenda legislativa da CNI (2015 a 2017)

\begin{tabular}{|l|l|l|l|l|l|l|l|l|}
\hline $\begin{array}{l}\text { Custo de } \\
\text { financiame } \\
\text { nto }\end{array}$ & $\begin{array}{l}\text { Infrae } \\
\text { strutur } \\
\text { a }\end{array}$ & $\begin{array}{l}\text { Infraestru } \\
\text { tura social }\end{array}$ & $\begin{array}{l}\text { Interess } \\
\text { setorial }\end{array}$ & $\begin{array}{l}\text { Legislação } \\
\text { trabalhista }\end{array}$ & $\begin{array}{l}\text { Meio } \\
\text { ambien } \\
\text { te }\end{array}$ & $\begin{array}{l}\text { Questões } \\
\text { instituciona } \\
\text { is }\end{array}$ & $\begin{array}{l}\text { Regulamentaç } \\
\text { ão } \\
\text { economia da }\end{array}$ & $\begin{array}{l}\text { Sistema } \\
\text { tributári } \\
\text { o }\end{array}$ \\
\hline 5 & 24 & 8 & 66 & 50 & 21 & 8 & 32 & 35 \\
\hline
\end{tabular}

Fonte: os Autores (2018)

Em seguida, a distribuição dessas proposituras graficamente:

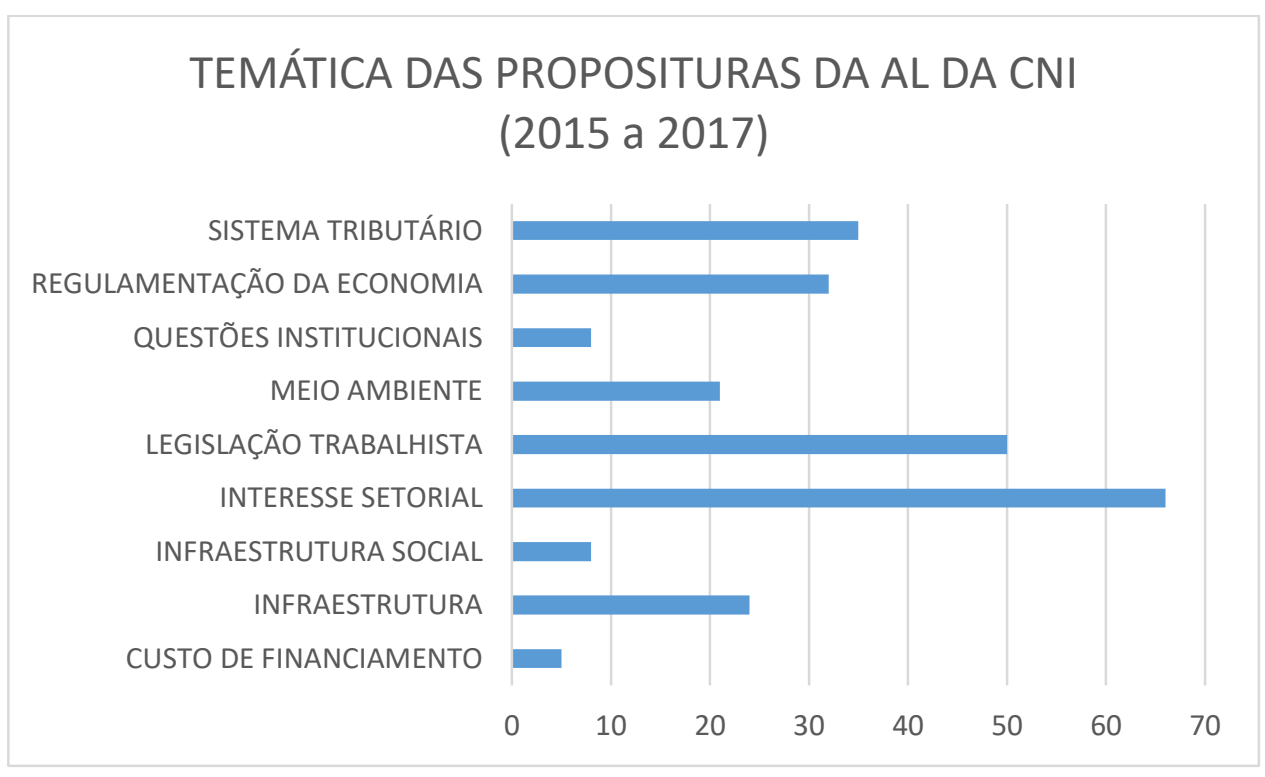

Fonte: os Autores (2018)

Quando falamos de temática das proposituras da Agenda Legislativa da CNI, notamos que o tema que mais mobiliza a agenda é interesse setorial, que representa 66 casos, dos 249 do universo 
total de matérias legislativas. A temática do interesse setorial representa os setores industriais organizados nas Associações Nacionais de Industriais, que participam da construção da AL da CNI, e nela inserem suas demandas, ocupando assim um lugar de privilégio na AL.

Em segundo lugar, a temática que mais aparece na AL da CNI é legislação trabalhista, que apresenta 50 casos, dos 249 projetos apresentados, seguido pela temática do sistema tributário com 35 casos e regulamentação da economia com 32 casos. Notemos que a maior parte da agenda é composta por interesses coletivos

Notemos que dos 22 projetos que viraram nova norma jurídica, 10 deles foram apresentados pelo poder executivo:

Projetos da AL da CNI que se tornaram novo a norma jurídica (2015 a 2017)

\begin{tabular}{|c|c|c|}
\hline GLA & & \\
\hline PLC 2/2015 & $\begin{array}{l}\text { Acesso ao Patrimônio Genético e ao Conhecimento } \\
\text { Tradicional Associado }\end{array}$ & $\begin{array}{l}\text { Poder Executivo (PL } \\
7735 / 2014)\end{array}$ \\
\hline MPV 664/2014 & Alteração de Benefícios Previdenciários & Poder Executivo \\
\hline L 2177/2011 & Código Nacional de Ciência, Tecnologia e Inovação. & $\begin{array}{l}\text { Deputado Bruno } \\
\text { Araújo (PSDB/PE) }\end{array}$ \\
\hline $\mathrm{CD} 4 / 2$ & com Deficiência. & $\begin{array}{l}\text { Senador Paulo Paim } \\
\text { (PT/RS) }\end{array}$ \\
\hline L 3672/ & $\begin{array}{l}\text { is da indústria nacional em Programas } \\
\text { ca. }\end{array}$ & $\begin{array}{l}\text { Senadora Ana Amélia } \\
\text { (PP/RS) }\end{array}$ \\
\hline IPV 668, & uotas de PIS/Pasep-Importação e & Poder Executivo \\
\hline LP 366/2 & e serviço & $\begin{array}{l}\text { r Romero Jucá } \\
\text { 3/RR) }\end{array}$ \\
\hline PLS-C 354/2 & lo tributár & $\begin{array}{l}\text { Senadora Kátia Abreu } \\
\text { (PMDB/TO) }\end{array}$ \\
\hline MPV 665/2014 & esemprego e Abono Salarial. & Poder Executivo \\
\hline PL $6459 / 2013$ & \begin{tabular}{|l}
$\begin{array}{l}\text { Obrigações gerais para produtores integrados e as } \\
\text { agroindústrias integradoras }\end{array}$ \\
\end{tabular} & $\begin{array}{l}\text { Senadora Ana Amélia } \\
\text { (PP/RS) }\end{array}$ \\
\hline PL 4567/2016 & \begin{tabular}{|l|} 
Exclusão da obrigatoriedade de participação mínima da \\
Petrobras na exploração de petróleo em áreas do pré-sal \\
\end{tabular} & $\begin{array}{l}\text { Senador José Serra - } \\
\text { PSDB/SP }\end{array}$ \\
\hline PLC 125/2015 & Pequenas $\mathrm{F}$ & $\begin{array}{l}\text { ado Barbosa } \\
\text { PDT/PR) }\end{array}$ \\
\hline SCD 24/2015 & $\begin{array}{l}\text { as da indústria nacional em Programas } \\
\text { ica (PEEs) }\end{array}$ & $\begin{array}{l}\text { Senadora Ana Amélia } \\
\text { (PP/RS) }\end{array}$ \\
\hline$/ 2015$ & SS e & $\begin{array}{l}\text { Senador Romero Jucá } \\
\text { (PMDB/RR) }\end{array}$ \\
\hline PL 4069/2015 & $\begin{array}{l}\text { Ampliação do prazo para a implantação do Sistema Nacional } \\
\text { de Controle de Medicamentos. }\end{array}$ & $\begin{array}{l}\text { Senador Humberto } \\
\text { Costa (PT/PE) }\end{array}$ \\
\hline PL 7735/2014 & \begin{tabular}{|l} 
Acesso ao patrimônio genético e ao conhecimento \\
tradicional associado.
\end{tabular} & Poder Executivo \\
\hline & $\begin{array}{l}\text { Alteração das regras para o auxílio doença e pensão por } \\
\text { morte. }\end{array}$ & Poder $\mathrm{E}$ \\
\hline
\end{tabular}




\begin{tabular}{|l|l|l|}
\hline PLV 6/2015 & $\begin{array}{l}\text { Elevação das alíquotas de PIS/PASEP - Importação - e } \\
\text { COFINS Importação. }\end{array}$ & Poder Executivo \\
\hline PL 6787/2016 & Valorização da negociação coletiva & Poder Executivo \\
\hline MPV 762/2016 & $\begin{array}{l}\text { Amplia o prazo de isenção do AFFRM, até 2019, para } \\
\text { navegação de cabotagem nas Regiões Norte e Nordeste }\end{array}$ & Poder Executivo \\
\hline MPV 752/2016 & $\begin{array}{l}\text { Prorrogação dos contratos do Programa de Parceria de } \\
\text { Investimentos (PPI) }\end{array}$ & Poder Executivo \\
\hline MPV 765/2016 & $\begin{array}{l}\text { Instituição do Bônus de produtividade para Auditor Fiscal, } \\
\text { Auditor Fiscal do Trabalho e conselheiros do CARF }\end{array}$ & Poder Executivo \\
\hline
\end{tabular}

Fonte: os Autores (2018)

Para o período 2015-2017, tem-se que quando a CNI posicionou-se como convergente obteve, desconsiderando-se somente as propostas apensadas, 68 propostas correspondentes e 10 não. Quando posicionou-se divergente, obteve 18 correspondentes e 32 não. Portanto, no primeiro caso obteve 87,17\% de correspondência e 12,82\% de não-correspondência. No segundo caso, com posição divergente, obteve $36 \%$ de correspondência. Considerando-se somente as 31 proposituras com decisão legislativa, o total de correspondência é estabelecido em invejáveis 70,96\%.

\subsection{AS AGENDAS LEGISLATIVAS DA CUT E DA CNI}

Em seguida, são apresentados os dados de posicionamento e resultado das duas entidades avaliadas. Esses dados foram analisados acima, mas aqui são expostos em conjunto, a fim de que se tenha uma visão ampla dos números do acompanhamento legislativo realizado pelas entidades. Assim, observa-se o seguinte:

Posição relativa às proposituras (CUT e CNI)

\begin{tabular}{|l|l|l|}
\hline Posição em relação às proposituras & N (proposituras) & Porcentagem (\%) \\
\hline Proposituras convergentes CUT & 6 & $3,77 \%$ \\
Proposituras convergentes CNI & 78 & $49,05 \%$ \\
Proposituras divergentes CUT & 25 & $15,72 \%$ \\
Proposituras divergentes CNI & 50 & $31,44 \%$ \\
Total & 159 & $100 \%$ \\
\hline
\end{tabular}

Fonte: Os Autores, 2018.

Em conjunto, as entidades avaliaram 159 proposituras com posicionamento pelas entidades no período, sendo que a CNI avaliou 128 (com predomínio de posicionamento convergente), enquanto a CUT avaliou 31 (com predomínio para posicionamento divergente - reativo).

Quanto aos resultados, observou-se o seguinte: 
Resultado do acompanhamento legislativo em relação ao posicionamento da entidade (CUT e

$\mathrm{CNI})$

\begin{tabular}{|l|l|l|}
\hline Posição em relação às proposituras & $\mathrm{N}$ (resultado) & Porcentagem (\%) \\
\hline Correspondência CUT & 4 & $3,77 \%$ \\
Correspondência CNI & 22 & $49,05 \%$ \\
Não-correspondência CUT & 3 & $15,72 \%$ \\
Não-correspondência CNI & 9 & $31,44 \%$ \\
Total & 38 & $100 \%$ \\
\hline
\end{tabular}

Fonte: Os Autores, 2018.

Considerando-se o conjunto, foram 38 proposituras com tramitação encerrada no período avaliado. Dessas, foram correspondentes aos interesses da CUT 4 proposituras (10,52\%), enquanto 3 não foram correspondentes aos seus interesses manifestos $(7,89 \%$ do total incluindo as duas entidades). A CNI, por seu turno, pode verificar que 22 proposituras foram correspondentes aos seus interesses (57,89\%), enquanto 9 não foram correspondentes (23,68\% do total).

\section{CONCLUSÃO}

Assim, a correspondência da CNI pode ser considerada alta, ficando em 70,96\%, caso se considere somente os casos com decisão legislativa. A alta correspondência entre os interesses da entidade e o resultado do trâmite legislativo concentra-se ainda mais quando a CNI adota uma postura menos reativa - de modo inverso ao ocorrido quando do "Lobby No Congresso Nacional", de Mancuso e da hipótese sugerida nesta pesquisa. Nesse caso, considere-se, entre as proposituras favoráveis, um índice de 58,06\% de Correspondência Positiva e apenas 12,90\% de Correspondência Negativa, o que sugere ganhos efetivos. Verifica-se, assim, que a posição convergente refletiu mais ganhos no conjunto de propostas tramitadas. Considere-se, ainda, que nessas ALI, a CNI posicionou-se mais como convergente (78 contra 50 divergentes), sendo que 121 proposituras não tiveram posicionamento em 2017.

A CUT apresentou uma postura mais reativa. Nas ALCUT, foram encontradas 31 proposições acompanhadas. Destas, 6 foram convergentes (19,4\%) (todas da Agenda de 2015) e 25 divergentes (80,6\%) (das demais Agendas). A entidade obteve o seguinte resultado: 4 proposituras correspondentes à sua posição manifesta $(57,14 \%)$ e 3 não (42,85\%). Entre as correspondentes (4 no total), a distribuição é igual (2 convergentes e 2 divergentes). Entre as não-correspondentes, todas as 3 são divergentes. 24 continuavam em tramitação, estando ausentes dessa análise.

Tem-se, assim, que no caso da CUT, quando a posição foi divergente, o índice foi de $50 \%$ para correspondentes e 100\% quando avaliadas as não-correspondentes. Os valores, mais uma vez, não estão de acordo com a hipótese de que uma posição reativa por parte da entidade tende a ter maior 
correspondência. Quanto ao posicionamento convergente, são 50\% quando consideradas correspondentes, mas todas as não-correspondentes (3) estão entre as divergentes. Portanto, ainda que o $\mathrm{N}$ seja baixo, o que dificulta uma conclusão segura, não se pode sustentar essa hipótese - o que já havia ocorrido na análise dos dados da CNI.

O motivo é creditado à composição do Congresso mais "conservador nos costumes" e "liberal na economia", o que significa que mais atuante quanto à diminuição do "custo-Brasil", implicando cortes em direitos sociais por meio de proposituras como a "Reforma Trabalhista" ou da Previdência. Assim, nesse cenário mais hostil aos interesses manifestos pela Central sindical, a ALCUT se torna mais reativa - o que, ao invés de passar a representar mais ganhos, representa uma pauta mais dura à Central e culminando em derrotas aos seus interesses. Antes, portanto, que somente a posição inicial tomada (mais ou menos reativa), a composição do Congresso e os temas tratados são mais importantes para determinar a correspondência entre interesses manifestos e o resultado do processo legislativo ou não.

Deste modo, quando são verificados os temas das proposituras, tem-se que a partir de 2015 a pauta da CUT é sobejamente derrotada. Isso deveu-se, em grande medida, à agenda de flexibilização do trabalho proposta pelo novo Congresso. As proposituras acompanhadas em 2016 permaneceram em tramitação, contudo, obsoletas diante da "Reforma Trabalhista" de 2017, tiveram, via de regra, seu teor aprovado e transformado em nova norma jurídica.

Portanto, logo que a posição manifesta pela entidade (reativa ou não) não demonstrou enviesamento do resultado (apontando para uma maior ou menor correspondência), verificou-se a necessidade de uma análise mais atenta da Composição do Congresso Nacional, o que sugerimos para uma futura pesquisa com essa proposta.

Assim, pode-se concluir que a CUT definiu estratégias bem evidentes (de defesa de propostas em 2015 e reação nos demais anos), sendo que no total, resultados correspondentes aos seus interesses foram mais numerosos. Nesse ponto, cabe, contudo, a observação apontada acima. A maior parte das proposituras se mantinha em tramitação, e o teor negativo aos seus interesses foi em grande medida transformado em nova norma jurídica com a aprovação do PLC n 38/2017.

A entidade também se posicionou em relação a um menor número de proposituras que a CNI, adotando uma estratégia mais focada (pelo menos no que se refere à Agenda Legislativa). Não se pode, com isso, todavia, afirmar que CNI não priorizou algum projeto específico, realizando um lobby mais preciso para alguma matéria. Pode-se concluir apenas sobre a pressão realizada por meio das Agendas. Ainda assim, considerando-se o N baixo para os dados da CUT, conclui-se pela necessidade de tomar um período mais longo de avaliação - o que poderá ser feito após a 
publicação de novas ALCUT. No caso da CNI, a posição convergente (não-reativa) representou maior correspondência entre interesses e resultados, contrapondo-se à hipótese. Isso leva, então, à necessidade de se comparar um período mais longo e os dados do processo legislativo.

\section{REFERÊNCIAS:}

BOITO JR., M. (2010). O Sindicalismo deixou a crise para trás? Um novo ciclo de greves na década de 2000. Cadernos CRH, vol. 23, nº 59.

BOSCHI, R., DINIZ, E. (2000). Globalização e Elites Empresariais: padrões alternativos de relações entre os setores Público e Privado no Brasil. In: ANPOCS. Anais...Petrópolis: $24^{\circ}$ Encontro Anual da Anpocs.

CASTRO, M. B. de, et al. (2016). Agenda Legislativa da Indústria 2016. Brasília: CNI, , [s.d.].

COSTA, P. R. N., BORCK, I. S. S. F. (2017). Empresariado industrial e Legislativo: a Agenda Legislativa da CNI (2010-2017). In: ANPOCS. Anais...Caxambú: $41^{\circ}$ Encontro Anual da Anpocs.

COSTA, L. N. F. (2016). O Lobby dos Trabalhadores no processo constituinte de 1987-88: um estudo sobre a atuação do DIAP. Estudos Históricos, vol. 29, nº 59.

CUT. (2015). Agenda Legislativa da CUT para as Relações de Trabalho. Central Única dos Trabalhadores, vol. 1, n 1, p. 151.

CUT. (2016). Agenda Legislativa da CUT para as Relações de Trabalho. Central Única dos Trabalhadores, vol. 1, n. 2, p. 149.

DIAP. (2014). Radiografia do Novo Congresso: Legislatura 2015-2019. Brasília-DF: Departamento Intersindical de Assessoria Parlamentar.

DINIZ, E. (1997). Corporativismo em transição. In: DINIZ, E. Crise, Reforma do Estado e Governabilidade: Brasil 1985-95. [s.l.] Editora Fundação Getúlio Vargas. p. 11-39.

DOCTOR, M. (2002). Business and Delays in Port Reform in Brazil. Brazilian Journal of Political Economy, vol. 22, n 2, p. 79-101.

FACCI, N. (2017). O Lobbying da Federação das Indústrias do Estado do Paraná (Fiep): o caso da legislação do ICMS (2005-2015). [s.l.] Fundação Getúlio Vargas.

GUILMO, N. S., DEL PASSO, O. (2017). Legislação trabalhista: atuação política da CNI e CUT no segundo governo Lula. In: ANPOCS. Anais...Caxambú: $41^{\circ}$ Encontro Anual da Anpocs.

HARTMANN, J. A. (2015). Empresariado Industrial e Ação Política: A Federação das Indústrias do Estado do Paraná como Grupo de Interesse e Pressão (2003-2011). [s.l.] Universidade Federal do Paraná.

HOJNACKI, M. et al. Studying Organizational Advocacy and Influence: Reexamining Interest 
Group Research. Annual Review of Political Science, n. 15, p. 9.1-9.21, 2012.

MANCUSO, W. P. (2007). O lobby da indústria no Congresso Nacional: empresariado e política no Brasil contemporâneo. São Paulo: EDUSP.

MARTINS, L. (1985). Estado capitalista e burocracia no Brasil pós-64. $2^{\text {a }}$ ed. Rio de Janeiro: Paz e Terra.

SANTOS, M. L., MANCUSO, W. P., BAIRD, M. F. (2017). Lobbying no brasil: profissionalização, estratégias e influência. IPEA.

SCHMITTER, P. C. (1971). Development, Political Groups and Interest Politics. In: SCHMIT'TER, P. C. Interest Conflict and Political Change in Brazil. Stanford: Stanford University Press.

TATAGIBA, L., GALVÃO, A. (2019). Os protestos no Brasil em tempos de crise (2011-2016). Opinião Pública, vol. 25, n¹.

ZAMPIERI, E. (2013). Ação dos Grupos de Pressão no Processo Decisório das Comissões Permanentes do Congresso Nacional. E-Legis, vol. 6, n 12, p. 122-136. 